\title{
'Sans compassion nor will to answer whoever asketh the why': Personal sovereignty within black metal
}

\begin{abstract}
The importance of personal sovereignty in black metal cannot be overstated. After all, we are the 'wolves amongst sheep'. Presented here are the results of a documentary analysis (consisting of subcultural output and various studies) research project intended to analyse the wolf imagery in black metal wherever it may appear and regurgitate and reform these depictions in terms of their representations of personal sovereignty. For those who embrace the lycanthropic and colour their interactions with the world around them with hues of such dark, lupine tenets, this project will peruse these values through the philosophical kaleidoscopes. It will posit, hopefully convincingly, that the black metal subculture is rife with complications and contradictions - a paradoxical slant into a personal sovereignty that can never be attained, remaining frustratingly out of reach.
\end{abstract}

\section{KEYWORDS}

black metal subculture wolf personal sovereignty youth semiotics 
1. OED Online (2019), 'personal, S.v.', Oxford Living Dictionaries, Oxford Oxford University Press, http://www. oxforddictionaries. com/definition/ english/personal Accessed 25 April 2019

2. OED Online (2019), 'sovereignty, s.v.', Oxford Living Dictionaries, Oxford: Oxford University Press, http://www.oxforddic tionaries.com/defini tion/english/soverei gnty. Accessed 25 Apri 2019

3. The Christian Church and the Storting (Norwegian Parliament) share a unique relationship - 50\% of MPs elected to the Storting must be practising Christians. Although $76.1 \%$ of the population were members of the Lutheran Church of Norway in 2013 (from the Church's own statistics), only $22 \%$ actually believe in the existence of a God. This discrepancy is due to the fact that a Norwegian citizen is born a member of the Church and must opt out officially. Obviously, this presents a problem with a precarious balance of power, when $50 \%$ of a Government may only have a commonality with $22 \%$ of the population. Ergo, rebellion against Church and rebellion against State can be one and the same.
Personal, adj. belonging to or affecting a particular person rather than anyone else. ${ }^{1}$

Sovereignty, $n$. supreme power or authority. ${ }^{2}$

The title of this article is taken from 'Inno A Satana', Emperor's hymn to the Devil (Emperor 1994). In this line in particular, Satan is described as possessing a number of traits associated with personal sovereignty. The act of selfrule, a non-adherence with societal norms, wilful transgression presented as a lifestyle strikes a chord within the subculture. A lifestyle that in part recalls the Nordic berserker warriors; solitary peripatetic men transformed by a bestial will into their hammrammr (from the norse heim - the uninhibited, true self, and hamr - soul or clothing) (Duclos 1998). While in this 'form', the warriors were purported to be nigh-on invincible fighters; the term berserker (or, 'going berserk') states how a possession takes place which drives the subject into a reckless savagery (Duclos 1998). This article will analyse how the 'possession' of man by wolf offers symbolic permeations of how man rules and owns the self; how this animalistic force increases a desire to transgress and how transgression further feeds this animal-self.

As black metal races to be ever darker, aesthetically calling back to Hunt-Hendrix's haptic void discourse (Hunt-Hendrix 2010), pushing further beyond boundaries of blasphemy and immorality - proponents, on the advice of philosophers such as Nietzsche, have sought to emulate such behaviours as well as aesthetics. Self-rule has been a principle concept of black metal since the early days. Norwegian youths would rebel against the mainstream Christian culture that their homeland offered ${ }^{3}$ by inverting Christian values to levels of blasphemy. This famously progressed into much darker territory, but for the sake of this article we will consider the validity of the thought process involved as opposed to the acts themselves, for reasons that will become clear. Early on the limits of the actor's sovereignty were recognized in its basest terms of teenage rebellion, as one would expect. Claims of Nazi and Satanic beliefs were youthful expressions of rebellion (Moynihan and Soderlind 2003) and the need to be seen as 'evil', and in most cases, should not have been taken seriously - particularly a number of those expressing support for the Third Reich. The increasing maturity of the protagonists, the scene, the subculture and the assorted ideologies has cemented the distinction, reframing it into something unique, typified by the manifestos of countless artists: Ihsahn (formerly of Emperor) in particular has produced a wealth of material that offers a re-affirmation of what Satanic beliefs actually mean, which contrasts heavily the baiting of the playground-Satanism that typified the early days of the scene. In this article, we will be looking at how the relationship between black metal and personal sovereignty is symbiotic; feeding off each other and pushing each other to new conceptual destinations - far removed from cries of: 'I'm 16 now, and I'll do what I want'.

\section{The wolf as personal sovereignty/will to power}

The wolf has become the avatar for this attitude, from lyrical references to artist and band names, to visual art and beyond, the appearance of the wolf holds heavy significance. Consider these, from the aforementioned song 'Inno a Satanna' (Emperor 1994): 'Thou art the Emperor of Darkness / Thou art the 
King of Howling Wolves.' and further on: ' $\mathrm{O}$ ' mighty Lord of the night. Master of Beasts.' Emperor combine the concepts of being the 'Emperor of Darkness' with that of 'King of Howling Wolves', thus tying the two concepts together, not unlike the US band Wolves in the Throne Room; a band who while not themselves Scandinavian, embody an attitude and philosophy (while free of the aesthetic) that vaguely confers with that of the northern European bands, particularly in aspects of respect and reverence for the harsher elements that make up the world of flora and fauna. When we consider Wolves in the Throne Room, continuing from Morton's dissection of the numerous possibilities of what this appellation evokes (Morton 2013), a possible interpretation of this appellation is that the band are stating that the wolves are not intruders in the throne room, but the kings themselves, preying on their subjects both through their reigning position and amongst the wealth and treasures found there. Or alternatively still, as philosopher Bruno Latour is known to utilize the term 'wolf' to depict thinkers and philosophers in general, is there a possibility of a reference to Plato's 'Philosopher Kings' of Kallipolis (Plato 1991)? This broad association, in essence, draws together three concepts of sovereignty, wolves and philosophers.

We have come to a dilemma, however, which hinges upon how we define 'Master' as in 'Master of Beasts'. Are we looking at the noun form? So therefore, Satan is the leader of all beasts, or can we assume that the verbal form is implied; hence Satan has mastered how to control/manipulate beasts. This interpretation arises from research for the meaning of the wolf in black metal. Conflicting answers of the wolf being 'outside society' and 'master of society' when taken at their literal sense are confusing and contradictory. However, if we look at the possibility that an individual can be an outsider who has mastered the idiosyncrasies of society while remaining personally sovereign and true to itself. No individual questioned believed that they had any claim to ruling society, but many were adamant that their disdain for society, and in some cases humanity as a whole, came from a deep understanding of its machinations.

The differential between the wolves of personal sovereignty and the wolves in the throne room uncovers a principle difficulty with attainment of self-rule. When (read: If) self-rule has been achieved, the addition of any authority or responsibility, i.e. sovereignty over another person, system or position immediately defeats the notion. Personal sovereignty is lost and the results are twofold; one must take appropriate responsibility for something or someone else and a ritual of rejoining the social order is a necessity for such a transference of care to take place. Not only does this individual hold a degree of true sovereignty over the subject but must submit themselves to the dominance of a mainstream system or culture in order to perform their role properly. Thus the natural order of progression through life: maturing, work/career, family, can all be succinctly described as obstacles to personal sovereignty.

Derrida in his 'La Bête ou le Souverain' lecture series creates a three-tiered approach to animalistic behaviour, using the trio of dog, wolf and man. He creates a hierarchy that reads thus: the dog being below man, domesticated, reliable, controllable and subjugated to man. The wolf is man's fear - sovereign, aggressive, fearsome. Finally man, who due to his humanity and desire for civilization, community and other (attained) Nietzschean weaknesses, sits 
in the centre of this paradigm (Derrida 2009). This triad also appears in the following lyric:

I'm not man disguised as dog

I'm wolf disguised as man

society created me and finally denied the existence.

But remember, the hunter only kills the wolf... it's in the fairy-tale world.

(Kadenza 2005)

The ascent between species is made quite clear. The narrator is ascending from humanity to lycanthropy. So while humanity hunts and kills the wolf in retaliation for their fear and the transgressions committed, the wolfoid is among them unhindered. The lyric finishes on a bleak, cautionary morale: man only kills wolf in the fairytale world. In reality, the odds are irreconcilably reversed.

\section{The wolf as Satanic imagery}

Returning to the idea of Satanism, Peter H. Gilmore, the High Priest of the Church of Satan, an esoteric Satanist Church, denotes:

[...]Satan is a symbol of Man living as his prideful, carnal nature dictates. The reality behind Satan is simply the dark evolutionary force of entropy that permeates all of nature and provides the drive for survival and propagation inherent in all living things. Satan is not a conscious entity to be worshiped, rather a reservoir of power inside each human to be tapped at will.

(Gilmore n.d.)

As a Satanist, Gilmore promotes the idea of man returning to prideful and carnal nature, this corresponds to the call for a return to man's bestial state, a primal past so to speak, espoused in the philosophical musings of Negur区 Bunget or bemoaning that progress has robbed humanity of the wisdom gleamed from atavistic states. Echoing the message of Burzum, particularly on the track 'Feeble Screams from Forests Unknown'. Interestingly, both views maintain that this potential is already inside man: 'Homo homini lupus est' ('Man is man's wolf'). As Nietzsche declared, man chooses to be subject to Christianity (to this we can add morality, society, etc.) and represses the carnal, bestial, prideful, or to put it simply 'Satanic' state. No man can truly be aware just how far that his contemporaries can tap into this mindset, disguising lupine man's intentions. Adopting the black metal wolf as a spirit animal is just one way that an individual can recall this primal spirit. Humanity enhanced with the ability of transgressing social norms and becoming something that is a danger to the masses of humanity still under the control of the denigrating influences of modernity. Becoming man's wolf - a predator of fellow man, a shadow figure unknown to others, perhaps forcing its way or being granted entry (as a result of its prowess) into the throne room.

\section{The wolf: An impact on subculture}

This new twist on the idea of subculture, an 'asocial subculture' implies that while black metal IS a subculture, its component members are loners responding to the same cultural triggers, as opposed to a united front or any kind of 
tribal expression. This in itself presents a problem for all current subcultural theory. Initially, Euronymous' Helvete record store operated as a hub for the nascent Norwegian scene. In general, such places, social hubs for the black metal subculture are few and far between; that is if they exist at least with anywhere near the same level of infamy. This results in scene members who are outside of the upper echelons of the subcultural hierarchy forced into defining their allegiances alone or in smaller numbers, as pockets of scenes erupt everywhere. A cursory glance on Metal Archives offers an insight into the numerous countries and cities that have given birth to enough local black metal artists to legitimately compose a scene. However, for those who live outside of such pockets, their access to them (and countless others worldwide) is made easier by the existence of the Internet.

The sovereign nature of the black metal subculture has resulted in a 'glocalizing', bricolage effect; a variety of local features can be rearranged and juxtaposed to supply new meaning to previously available tropes. This is how glocalization occurs, as participants associate and change things to be in line with what they understand and have experience of, moulding a concept to fit in with local knowledge. One can watch the transition between the industrial sludge that typified the music and lyrics of Black Sabbath, replaced by the strippers and cocaine-fuelled misadventures of Mötley Crüe, finally arriving at the bleak stark forested landscapes and darkness portrayed by Burzum et al. There is little conceivable way that Norwegian black metallers could fully share common values as espoused in lyrics and context with bands like Mötley Crüe or Black Sabbath, perhaps only seeing kindred spirits in increasingly vague terms of musical and aesthetic construction.

Divergences from the monolithic shadow of Satanic black metal empower followers in redefining and reframing their space. The most telling instance of cultural variation influencing the subculture is that of different iteration's of the subculture's attitude towards the wolf. In Norway, possibly because of the current prevalence of wolves in the wilderness, a Norwegian black metaller would be more likely to personify the wolf and to indicate a spiritual kinship. Hearing respondents claim that 'we' are the wolves was a common occurrence. The wolf in Norway takes on a legendary reverence among the faithful; cunning, solitary, wise and powerful. The Norwegian symbolic wolf acts as a consistent allusion to the creature's bestial nature and willingness to survive, to hunt and kill. This wolf is a closer reflection of the animal itself. The Norwegians talk of a hierarchy between human laws and bestial nature. By embracing their 'wolf-selves' they transcend this distinction, symbolically no longer seeking protection under the laws made by the weak, for the weak. This is the ultimate statement of both otherness and sovereignty. They are effectively creating segregation from the herds of sheep. It is possible to assume that the arsons and macabre acts that saturated the Second Wave are an indirect result of this liberation. The wolf that the English black metallers speak of differs in quite visible ways. In contrast to the Norwegian ' $w e^{\prime}$, the English prefer a more distant relationship. The English wolf is less naturalistic and resonates more with fairy tales and constructions. Essentially, the English wolf is 'they', this iteration encompasses more imagined approximations of what 'evil' is, the inverse of the moral 'good' for instance. Such is the existence of the wolf in mythology, either metaphorical or literary. The totemic relationship between this wolf and the faithful contrasts the personified wolf of Norway. Once again, a possibility for this difference is the distinct lack of wolves in the English countryside, whereby there exists a more fluid template 
for what this creature can be and consequently, a more fluid application on how the faithful can align themselves alongside it.

Interestingly, when pressing Scottish black metallers on the subject, the responses showed shades of both English and Norwegian depictions of the wolf, although heavily influenced by the Scandinavians. Two lines of thought can be drawn from this. Firstly, in accordance with the idea of the presence of wolves affecting the concept of the creature itself, rural Scotland has been home to wolves far more recently than its neighbour to the south of Hadrian's Wall. Secondly, Viking invaders from Norway landing in Scotland left an imprint on the culture that survives more readily. By way of example, please consider the following prose:

On Ederachillis' shore

The grey wolf lies in wait-

Woe to the broken door,

Woe to the loosened gate,

And the groping wretch whom sleety fogs

On the trackless moor belate.

The lean and hungry wolf,

With his fangs so sharp and white,

His starveling body pinched

By the frost of a northern night,

And his pitiless eyes that scare the dark

With their green and threatening light.

He climeth the guarding dyke,

He leapeth the hurdle bars,

He steals the sheep from the pen,

And the fish from the boat-house spars,

And the digs the dead from out of the sod,

And gnaws them under the stars.

Thus every grave we dug

The hungry wolf uptore,

And every morn the sod

Was strewn with bones and gore:

Our mother-earth had denied us rest

On Ederchaillis'shore.

(Ogilvy 2010)

This lyrical piece describes the actions of a single wolf on a coastal settlement in Scotland. In short, a wolf had been attacking and desecrating the graves of the village dead and then eating the remains. In response (after the poem's narrative has ended), the locals, having grown increasingly tired of this practice, began to bury their dead on a rocky piece of land just off the shoreline, at great effort to themselves. The single instance where the wolf is described as having a vaguely anthromorphic quality; the 'pitiless eyes' offers a glimpse into the terrifying otherness of the wolf. Considering the eyes as the window to the (human) soul, to find a complete lack of pity, a distinctly human trait only increases our cognizance of the wolf as the completely alien to our understanding. Breaking a considerable taboo of necrophagism echoes an early version of the 'Little Red Riding Hood' story in which the wolf encourages the protagonist to cannibalize her grandmother's remains. 
Essentially this wolf is presented as a more literal creature than that of the English black metallers. The wolf is almost completely unknown and unknowable, described only its actions, its hunger and cruelty. This wolf is sovereign as it is not only the solitary predator, but completely dismissive of social orders concerning respect for the dead.

The wolf on Ederachillis' Shore may be described as having 'pitiless' eyes; pitiless and its synonym cruel are mutually exclusive in this context, as cruelty is an active personality trait. One cannot describe actions central to the wolf's survival as cruel, and therefore by no means is it evil either. This wolf is merely surviving. An unintended consequence of the grave-robbing is that the dead are 'denied rest', but even this is only a problem on a spiritual level, if belief is applied. It may be ingrained deeply into our morality, but the wolf has no regard for this being a particularly malevolent act. In a way, the wolf is stealing sheep, fish and the dead. It is not killing and eating children and/or people, which would be on consideration much worse. If we look at this in terms of personal sovereignty, the wolf is transgressing social boundaries with complete ignorance of their existence. Not transgression for transgression's sake. This constructs an issue for practitioners of self-rule within the black metal community. The individuals who emphatically declare ' $N O^{\prime}$ to society and its rules, placing themselves as opposition, are still summarily defined as subject to those rules. The wolf is unaware of them and therefore its transgressions have a different meaning. If we want to attach a word to transgression strictly by rejection of societal rules, may I interest you in the classical idea of 'sinning' as a more reasonable alternative? In this new respect, true transgression is no longer oppositional but selfish and apathetic.

\section{Fauna and blackening activity}

US band Fauna's album The Hunt: A Mythic Journey in Seven Parts typifies the congruence between the trials of man and wolf. The track can again be understood better when viewed through Derrida and Deleuzean ideas of deconstruction, of which I give regard to Steven Shakespeare for introducing me to this particular connection in his work 'Of plications: A short summa on the nature of Cascadian black metal', (Shakespeare 2012). The narrative of the song describes hunting parties of both primitive man and wolf and follows the similarities. After initially beginning their travails and their very existences for the same reasons:

Flung from our origins,

Into an emptiness that consumes

We dwell within a void.

(Fauna 2007)

This world offers no purchase, we live on dust and stone.

(Fauna 2007)

This world offers no purchase - without actively hunting for food; both will diet on dust and stone. For survival's sake, the hunt must go on. The two hunting parties then diverge, each narrates its own alternate stanzas, whilst maintaining this spiritual link, a recurring reminder of the oneness of wolf 
and man: 'Great One, Let my spirit soar / Let us ascend ever onward.' (Fauna 2007). Even though the methods employed by each actor differ:

My arrow is a seal

A covenant with life

My spear is a seed

I plant in the womb.

(Fauna 2007)

Blood in the tracks,

assent begets assent.

(Fauna 2007)

We, as witnesses to this event, never lose sight of the hunt's true purpose: survival. The arrow, the 'covenant with life' used by man, represents a deal between man and God, or as here, man and life (both narrators go to lengths to not name this deific entity that symbolically associates with them). A deal written in the blood of the prey that in exchange for the juncture of the life taken and the sacrifice, life will continue. The symbolism of the spear as a seed to be planted in the womb attempts once again to forge that link between humanity and a life force; essentially death begets new life. This is analogous to the transition from discontinuous to continuous states of being. Abrahamic Covenant demands that whoever reneges on this deal suffers a fate equal to the sacrifice.

The closing couplet 'I feast on glory / When two become one again.' (Fauna 2007) highlights the reunification of species as well as the blood offering to the Gods in return for survival. This is a partial return to discontinuous life, but the sharpness of this particular precipice reminds us just how easily the switch between states can be administered. The album bears the text 'Shamanic black metal atavism', thus tying the ancient hunting styles of both man and beast to something ritualistic, this envelopes the lifestyle of black metal. What appears normal and perfectly functional at the time can be elevated to something spiritual; the subtitle speaks of a 'mythic journey', foreshadowing the wholly spiritual nature and the necessity to navigate it. Applying this to real life, the magick falls noticeably short; the sovereignty gained from blazing a trail through the hunt disintegrates. In Morton's work, Wolves in the Throne Room express dismay at accusations of 'hypocrisy' creating music that overtly praises the values of primitivism and the forested landscape on electric instruments (Fauna 2007). This in itself is an example of sovereignty, the musicians make that choice to sound how they do, and on how they do it, without a care for the opinions of others. The message would be the same played on anything.

Such as with the tools of music, the tools of death have changed too, from 'arrows' and 'spears' to 'Nuclear Annihilation'. This returns us to the subculture, how the faithful participate in interacting with the world outside the nigredo. We accept that our tools have changed, but survival is still the pinnacle requirement and meaning of life. Whilst society rationalizes the pursuit of material gain as the replacement for the soulful pursuit of survival, black metal teaches us to remain true to the Earth. It replaces outward frivolities with the necessities of life which are to be made aware of: strength, power, continued existence and eventual death.

Much is made in black metal of reverence to nature and a support for a primitivism and return to man's bestial state. One question that remains: is 
this return symptomatic of a step towards and eventual embrace of nature itself, or a violent response in the rejection of humanity? Much like in 'The Hunt' while methods and direction of travel may differ conceptually, the results are much the same. The same action that involves leaving the human world with its rules behind, also engenders the individual to a whole new order: that of the natural world. The animal kingdom has its own hierarchy and practices. This would require submission, new rituals would have to be learnt; hunting, warmth, communication, the freedom that one would hope for in this pursuit is illusory.

From another perspective, invading the 'world-for-itself', or noumenon as Kant would term it, irrevocably transforms this world into a world-for-us. The presence of the outsider would corrupt the delicate balance that maintains the impetus of each society, and would forever change it. In this Kantian scenario, mere entry to this new society of flora and fauna would cause it damage consequently, the kingdom would be wholly different and unlike the natural existence that the wanderer hoped to find.

\section{Keeping the 'faith'}

To maintain the illusion of personal sovereignty, Varg Vikernes has become adept at historical revision, going as far as claiming that the two Burzum albums recorded during his incarceration for the murder of Euronymous and the arson of several churches: 'Dauði Baldrs' (1997) and 'Hliðskjálf' (1999) in a dark ambient style, were due to a disillusionment with black metal. However, it is worth noting that while incarcerated, Vikernes was unable to have access to real instruments. Whether this was a defining factor on the stark change of direction (which was abandoned post-incarceration, although recently resurrected) or not is unknown, but claiming personal responsibility for the genreshift is embodying the sovereign wolf that Vikernes names himself after.

Fenriz, of Darkthrone, is another artist who has changed his perception of his own past works - namely his blackened folk projects Isengard and Storm, saying that he would not touch Storm's album Nordavind (1995), created alongside Satyr Wongraven, with a '666-foot pole' (Patterson 2013). By dismissing these past folk/black metal hybrids (although appreciating that as separate genres they are both perfectly fine), he not only attempts to maintain his sovereignty against his own earlier action; but also treating his wolf as a wolf that lives in the here and now. As an artist, sovereignty over one's own work is achievable, however, living in the here and now, and rebuilding one's narrative on a regular basis proves difficult when applied to using black metal to navigate spatial relationships. This manner of sovereignty can not only easily attract derision, but erect obstacles daily, as one has to consider just what event causes the narrative to switch direction, applying meaning in retrospect. When moving through life is based on personal experience, if we are continually shifting narrative, making our own self discontinuous, each day becoming someone new, deciding on the best course to take future paths becomes difficult if not impossible. Today's decision is not necessarily tomorrow's.

\section{Personal sovereignty and post-morality}

Personal sovereignty can be seen as both a Satanic response to the dominant culture, and more interestingly, the removal of self from this binary of good vs. evil. If one chooses self-rule in any form, one is attempting to escape the 
dominant culture's moral codes, not in order to violate them, which would be the obvious Satanic inversion response, but an entry into a state of postmorality. Whereby, the post-moralist acts solely for themselves, regardless of society's rules.

Respondents commonly said that adopting the wolf as a spirit animal and following its 'teachings' gave them confidence in their ability to surpass the morality of others. They feel 'liberated' and free or completely distanced from society's judgement. They lose, if only at a personal level, the hindrance of society's laws and standards. By self-declaration of the 'wolf in man', the black metal faithful are effectively putting themselves outside the norms of culture. E of Swedish black metal band Watain offered the following:

I think we can all feel disgusted by corpses and the smell of blood and I think that is great. It hardens you and it gets you to the point where you do not give a fuck. It takes a knife and it cuts that part of your brain out and leaves it backstage because you can't take it onstage with you.

(Doran 2012)

He indicates an awareness of that human aspect of disgust at such stimuli, but forcefully severing it from your life in order to be closer to the wolf.

\section{Ulver and the wolf in man}

In 1997, the Norwegian band Ulver released Nattens Madrigal- Aatte Hymne til Ulven i Manden through Century Media, their first internationally distributed release. The album consists of eight tracks, or 'hymns to the wolf in man', a concept that perfectly mirrors the will of its creators. Ulver offer a concept of the wolf as a spirit within man, allowing man to become something more, recalling Derrida's three-tiered approach discussed earlier. They offer multiple tributes, each emphasizing an individual characteristic of the lycanthrope and its interaction with the world around it. The album's cover by Tania 'Nacht' Stene features the familiar black metal staple of the landscape at night, with the silhouette of a lone, howling wolf against the backdrop of a single tree and a low moon. The cover celebrates its singularity; the wolf in the centre suggests that the individual is at the centre of all things. The solo, silhouetted form offers both a sense of mystery and purposefully maintained distance from society, as in the unknown of potential darkness within man. Additionally, the wolf, and therefore mankind, appears darker against the illuminated light. Already, we are presented with numerous references to the sovereignty of the wolf in man and the pride of place of such right at the centre of this opus' vision.

Each of the album's songs is presented in the form 'Of Wolf \& ...' placing the man-wolf in the initial position, implying that each of the following spaces, ideas or themes ('... Fear', '... The Devil', '... Hatred', '... Man', '... The Moon', '... Passion', ' ... Destiny' and finally, '... The Night') is only relevant if they engage with the protagonist. Keeping the sovereignty of the wolf intact as it navigates the obstacles placed in its path, choosing its own method. Sonically, the famously extremely lo-fi soundscapes culminated in another 'stepping stone' (Ulver 2012) in the evolution of the band. Dismissed but not disregarded as a piece of work, they treat it as a necessary flirtation. Even now, outside the commonly observed black metal subculture, Ulver's insistence on making music their way earmarks them as an example of a band working to a personal sovereignty, as per the wolves they name themselves after. 
In contrast to Fauna, who separate the wolf from man, but offer the spiritual connection. Ulver incorporate them both from the beginning; the opening song charts a bonding between man and wolf, as a Satanic offering. This gift bestowed upon the now-man-wolf freedom from God's slavery. Whereas Fauna observe a constant channel for spirituality within their work, the prey offered as ritual sacrifice, Ulver's man-wolf has little connection to anything spiritual besides the initial Satanic-bonding process. Interestingly, the language of plurality playing between the two releases should be noted. Fauna sing of 'we' the primitive hunting party; even with a single narrator, the group dynamic is at the forefront - a comradeship bonding the party together. Ulver's man-wolf the 'Wanderer' is always singular, always alone.

\section{The problems with personal sovereignty}

One has to consider whether the black metal subculture actively takes a step away from society or a step towards nature. This presents its own difficulties in that if walking away from society and its weakness is a declaration of personal sovereignty, we enter a society of one. A society without predetermined rules, but what is personal sovereignty without transgression? If the wolf just existed in the wilderness and bothered no one and interrupted nothing, would it cease to be sovereign, in that there is no reason for it? Sovereignty is immeasurable without transgression of societal rules, but as already discussed - he who acts as a sovereign wolf must do so without knowledge of or complete apathy towards such rules, or else their sovereignty is only going to be defined by the rules they disobey, and transgressions would be interpreted as sin.

If we alternately decide that the black metallers are, instead of taking a step away from society, taking a jubilant step towards nature, they are certainly releasing themselves from the shackles of humanity, but subsequently submitting to the order of nature. Therefore, personal sovereignty is once again rendered without validity.

The actual attainment of personal sovereignty in the contemporary era is impossible. The concept can only be actualized inside the art itself and in its creation. Only in one's art can self-rule take place, a state of being that can be shared by those experiencing the art for themselves. Whether exploring the mythically realized frozen tundra of Blashyrk with Immortal or re-enacting pagan rituals with Enslaved - the truth to personal sovereignty is that one must create a microcosm to reign over one's self in. Inside this conceptual world, it must be noted that whilst one is absorbed fully, the plane must be a world-for-itself, by definition. Black metal must always strive for personal sovereignty in art and thought; its pursuit is more pivotal than the access. This is how the subculture must exist, elevating the idea of self-rule, taking ownership of the concept.

\section{REFERENCES}

Derrida, J. (2009), The Beast and the Sovereign, Volume 1 (The Seminars of Jacques

Derrida) (trans. G. Bennington), Chicago, IL: University of Chicago Press.

Doran, C. (2012), 'Sympathy for the Devil', Metal Hammer, vol. 234, London:

Future Publishing.

Duclos, D. (1998), The Werewolf Complex, New York: Berg.

Emperor (1994), 'Inno a Satana', In the Nightside Eclipse, CD, England: Candlelight Records.

Fauna (2007), The Hunt: A Mythic Journey in Seven Parts, CD, England: Aurora

Borealis. 
Gilmore, Peter H. (n.d.), 'Satanism: The feared religion', Church of Satan, http://www.churchofsatan.com/satanism-the-feared-religion.php. Accessed 17 August 2015.

Hunt-Hendrix, H. (2010), 'Transcendental black metal', in N. Masicandaro (ed.), Hideous Gnosis, New York: Createspace, pp. 53-66.

Kadenza (2005), 'The Wolfoid', The Second Renaissance, CD, Japan: Holy Records.

Morton, T. (2013), 'At the edge of the smoking pool of death: Wolves in the Throne Room', in T. Morton (ed.), Helvete: A Journal of Black Metal Theory, 1: Incipit, Brooklyn, NY: Punctum Books.

Moynihan, M. and Soderlind, D. (2003), Lords of Chaos: The Bloody Rise of the Black Metal Underground, Washington: Feral House.

Ogilvy, D. (2010), A Book of Highland Minstrelsy, Whitefish, MT: Kessinger Legacy Reprints.

Patterson, D. (2013), 'Moonfog and Ulver: Folk and folklore in black metal part II', in D. Patterson (ed.), Black Metal: Evolution of the Cult, Washington: Feral House, pp. 397-406.

Plato (1991), The Republic: The Complete and Unabridged Jowett Translation, New York: Vintage Books.

Shakespeare, S. (2012), 'Of plications: A short summa on the nature of Cascadian black metal', in N. Masciandaro and R. Negarestani (eds), Glossator 6-Black Metal, New York: Createspace.

Ulver (2012), 'Ulver: Of wolves \& withdrawal', Black Metal: Beyond the Darkness, London: Black Dog Publishing.

\section{SUGGESTED CITATION}

Hoffin, K. (2019), "'Sans compassion nor will to answer whoever asketh the why": Personal sovereignty within black metal', Metal Music Studies, 5:2, pp. 151-162, doi: 10.1386/mms.5.2.151_1

\section{CONTRIBUTOR DETAILS}

Kevin Hoffin is a criminologist, currently lecturing at Birmingham City University. He has research interests in subcultures, youth crime, criminal justice and policing and has a lifelong love of metal music, particularly black metal. He spends his free time reading from an ever-growing collection of comics or listening to obscure black metal.

Contact: Birmingham City University, Curzon Building, 4 Cardigan Street, Birmingham B4 7BD, UK.

E-mail: Kevin.Hoffin@BCU.ac.uk

(1) https://orcid.org/0000-0003-2929-9547

Kevin Hoffin has asserted his right under the Copyright, Designs and Patents Act, 1988, to be identified as the author of this work in the format that was submitted to Intellect Ltd. 